\title{
Distanciamento entre Acadêmicos e Empreendedores em Contextos de Baixa Renda
}

\section{Divide Between Academics and Entrepreneurs of Low-Income Contexts}

\author{
Gabriela Pereira \\ IAG-PUC-Rio \\ gabriela_np56@yahoo.com.br
}

Marcus Wilcox Hemais

IAG-PUC-Rio

marcus.hemais@iag.puc-rio.br

Mariana Betine

IAG-PUC-Rio

marianabetine@gmail.com

Submissão: 04/06/2020

Aprovação: 07/10/2020

\section{RESUMO}

A literatura de marketing que discute o distanciamento entre os meios acadêmico e empresarial normalmente o faz atentando para a existência desse problema somente a partir da realidade de grandes e médias empresas, desconsiderando que essa questão pode ser ainda mais grave quando os casos de distanciamento ocorrem com empreendedores em contextos de baixa renda. Tal literatura também pouco reconhece quais aspectos relacionados ao planejamento de marketing seriam mais propensos a serem praticados e teorizados de formas similares, não havendo, assim, um distanciamento tão agudo entre os meios acadêmico e empresarial. Diante de tais lacunas na literatura, o presente estudo analisa como empreendedores em contextos de baixa renda operam seus negócios, para verificar se suas práticas se alinham/distanciam de ensinamentos do meio acadêmico. Para isso, foi realizada uma pesquisa qualitativa, com coleta de dados por meio de entrevistas em profundidade com nove professores universitários e oito empreendedores desse contexto. Os achados mostram que, em geral, práticas dos empreendedores pouco se alinham com ensinamentos acadêmicos quanto a análise ambiental, pesquisa de marketing e segmentação e posicionamento de mercado, porém se aproximam quando adotadas ações do composto de marketing.

Palavras-chave: baixa renda, empreendedor, distanciamento, meio acadêmico, praticante.

\begin{abstract}
The marketing literature that discusses the academic and practitioner divide usually does so by focusing on the existence of this problem only from the reality of large and medium-sized companies, disregarding that this issue can be even more serious when the divide occurs with entrepreneurs in low-income settings. Such literature also does not recognize which aspects related to marketing planning would be more likely to be practiced and theorized in similar ways, thus, not revealing such an acute distancing between the academic and business environments. In the face of such gaps in the literature, the present study analyzes how
\end{abstract}


entrepreneurs in low-income contexts operate their businesses, to verify whether their practices are aligned/distant from the teachings of the academic environment. For this, a qualitative research was carried out, with data collection through in-depth interviews with nine university professors and eight entrepreneurs in this context. The findings show that, in general, entrepreneurs' practices are not much in line with academic teachings regarding environmental analysis, marketing research and segmentation and market positioning, but they come close when adopting actions related to the marketing mix.

Keywords: Low-income, entrepreneurs, divide, academic environment, practitioner

\section{Introdução}

Segundo dados do Banco Mundial, a pobreza no Brasil atingiu, em 2017, cerca de 50 milhões de pessoas, ou seja, $25,4 \%$ da população brasileira vivia com aproximadamente $\mathrm{R} \$ 387,07$ por mês (BÔAS, 2018). O corte de programas sociais e o aumento do índice de desemprego estão diretamente relacionados a esse fenômeno (SOARES, 2018). O enxugamento de programas sociais, tais como o Bolsa Família, representou uma diminuição de até $60 \%$ na receita de famílias de baixa renda, e o índice de desemprego, em janeiro de 2018, chegou a 12,2\%, atingindo cerca de 12,7 milhões de brasileiros (GERBELLI; SARMENTO, 2018). Por consequência desse contexto, o número de trabalhadores informais cresceu: 986 mil brasileiros passaram a trabalhar por conta própria, enquanto que 581 mil indivíduos conseguiram novos empregos sem carteira assinada (GERBELLI; SARMENTO, 2018). Empreender, portanto, acabou se tornando um caminho para fugir do desemprego ou complementar a renda familiar.

Existem duas causas principais que levam uma pessoa a se tornar um empreendedor: oportunidade ou necessidade (DEGEN, 2008). No primeiro caso, o empreendedor inicia um negócio para buscar uma oportunidade identificada no mercado, enquanto no segundo caso o empreendedor é motivado por situações de desemprego ou insatisfação com seus empregos anteriores (FERNÁNDEZ-SERRANO; ROMERO, 2013). O número de empreendedores por necessidade tem crescido no Brasil em razão do aumento do desemprego, do baixo grau de educação formal da população e do aumento da pobreza, o que faz do empreendedorismo uma alternativa viável para indivíduos de baixa renda (GERBELLI; SARMENTO, 2018).

A falta de educação formal de empreendedores em contextos de baixa renda - apenas $14 \%$ dos empreendedores brasileiros possuem o ensino superior completo (GLOBAL ENTREPRENEURSHIP MONITOR, 2017) - dificulta o seu acesso a conhecimentos acadêmicos que poderiam mais bem prepará-los para gerirem os seus negócios. Isso ocorre tanto porque esses indivíduos possuem dificuldades de leitura e compreensão de textos que não sejam básicos, quanto porque sequer sabem quais são os tipos de conhecimento criados pelo meio acadêmico ou se esses seriam aplicáveis a suas realidades (VISWANATHAN, GAJENDIRAN; VENKATESAN, 2008).

Tal distanciamento entre os meios acadêmico e empresarial vem sendo discutido pela área de marketing há tempos, mostrando como existem teorias, conceitos e modelos que empreendedores e demais praticantes deveriam utilizar - mas, que pouco conhecem - para obter melhores resultados em suas práticas (LEE; GREENLEY, 2010; REPSOLD; HEMAIS, 2018). Todavia, a literatura de marketing que discute tal distanciamento normalmente o faz atentando para a existência desse problema a partir da realidade de grandes e médias empresas, especialmente aquelas dos Estados Unidos e da Europa (KLAUS; EDVARDSSON, 2014). Ao fazê-lo, desconsidera, portanto, que essa questão pode ser ainda mais grave quando os casos de distanciamento ocorrem com empreendedores em contextos de baixa renda em países, tais como o Brasil, fora desse eixo do mundo desenvolvido, i.e., indivíduos que pouco 
ou nada possuem de estudo formal escolar, muito menos universitário (PEREDO; CHRISMAN, 2006).

Adiciona-se a essa lacuna empírica o fato de que tais discussões em marketing escassamente analisam quais aspectos relacionados à disciplina seriam mais propensos a aproximarem os meios acadêmico e empresarial. A literatura da área até chega a propor ações que poderiam ser tomadas para aproximar ambas as partes (STANTON, 2006), mas pouco se conhece sobre quais aspectos relacionados ao planejamento de marketing (entre eles, análise ambiental, pesquisa de marketing, segmentação e posicionamento de mercado e composto de marketing) seriam mais propensos a serem praticados e teorizados de formas similares, não havendo, assim, um distanciamento tão agudo entre as partes.

Diante desse contexto, o objetivo do presente artigo é analisar como empreendedores em contextos de baixa renda operam seus negócios, a fim de verificar o quanto suas práticas se aproximam/distanciam de ensinamentos do meio acadêmico. Para isso, foi realizada uma pesquisa qualitativa, com levantamento de dados primários por meio de entrevistas em profundidade com nove professores de uma universidade privada do Rio de Janeiro e oito empreendedores em contextos de baixa renda - mais particularmente, em três comunidades localizados nessa mesma cidade -, a fim de se comparar seus relatos a respeito de quais teorias, conceitos e modelo de marketing seriam importantes para o sucesso empreendedor.

Após a introdução, o restante do artigo é dividido em cinco itens. $\mathrm{O}$ segundo discute o distanciamento entre os meios empresarial e acadêmico. $O$ terceiro debate $\mathrm{o}$ empreendedorismo em contextos de baixa renda. O quarto apresenta a metodologia adotada no estudo. A análise dos dados é feita no quinto item, enquanto que as considerações finais são tecidas no sexto.

\section{Distanciamento entre os meios empresarial e acadêmico}

A lacuna entre os meios acadêmico e empresarial é evidente em administração, em geral, e em marketing, em particular (HUNT, 2002). A razão para a existência deste distanciamento, entretanto, ainda não é clara, havendo uns que culpam o meio acadêmico, outros que dizem ser culpa do meio empresarial, enquanto alguns acreditam que é culpa de ambas as partes (LEE; GREENLEY, 2010). Todavia, o consenso que existe em relação a esse fenômeno é de que o problema está na essência dos objetivos de cada uma das partes quanto à análise de determinado fenômeno. Enquanto que, de um lado, acadêmicos buscam estudar fenômenos complexos, descrevendo-os detalhadamente e realizando longas e aprofundadas análises das características inerentes ao objeto pesquisado - o que, diversas vezes, significa analisar indústrias e suas particularidades, ao invés de empresas específicas -, de outro lado, praticantes pouco se engajam com o fenômeno, preferindo investir seu tempo na resolução daquilo que entendem ser o problema, em geral associado a questões próximas do seu dia a dia empresarial. Praticantes, portanto, são direcionados a ações de curto prazo, para solucionar problemas imediatos e específicos relacionados a suas empresas e atividades únicas, ao contrário de acadêmicos, que buscam respostas que levem à generalização de seus estudos, para que consigam desenvolver uma teoria que explique o fenômeno (BAINES et al., 2009).

Em nada ajuda a resolver essa questão o fato de praticantes pouco se interessarem por publicações acadêmicas (CROSIER, 2004). Essa baixa atratividade de pesquisas acadêmicas para tais profissionais de marketing deve-se, principalmente, a fatores como a linguagem formal e pouco acessível de artigos; a criação de modelos complexos, porém pouco aplicáveis à realidade empresarial; a falta de maior aprofundamento nos problemas reais de empresas; e a generalização de achados que, na verdade, somente são generalizáveis em um determinado contexto (REPSOLD; HEMAIS, 2018). Em razão disso, acredita-se que o impacto de trabalhos acadêmicos entre praticantes é limitado, o que acaba por minimizar a relevância de 
conhecer teorias, conceitos e modelos de marketing para se alcançar bons resultados empresariais (BROWNE; CUDDIHY, 2011). O empresariado acaba, então, possuindo pouca noção sobre as mais recentes teorias da área (ALMEIDA et al., 2010), pois não há intenção de absorver esses estudos à sua rotina; como efeito, acabam por incorporar ações de marketing de forma "parcial" ou "incorreta" (LILIEN, 2011).

É importante ressaltar que periódicos que publicam artigos de marketing tendem a ilustrar somente pesquisas que destacam conhecimento de marketing vindo do meio acadêmico. Mesmo nos periódicos que possuem um viés mais empresarial, a maioria das publicações tem origem em pesquisas da academia (CROSIER, 2004). Wierenga (2002) ressalta, entretanto, que conhecimento em marketing não deve ser pensado como sendo desenvolvido somente a partir de acadêmicos, para que então seja aplicado por praticantes. Para o autor, marketing deve ser entendido por uma ótica mais ampla, que também englobe conhecimento desenvolvido por praticantes, que seria tão válido quanto aquele produzido em universidades e think tanks. A base para tal conhecimento seria a experiência dos praticantes de marketing, que os ajudaria a formar modelos mentais para saber lidar com as diferentes variáveis do seu dia a dia empresarial e, assim, obter resultados favoráveis a seus negócios. Todavia, o meio acadêmico parece ignorar (ou, mesmo, desconhecer) tal conhecimento "prático", de forma que não o reconhece quando elabora o seu próprio conhecimento, incompatibilizando, assim, juntar ambas as formas de pensar.

Essa incompatibilização de conhecimentos leva alguns pesquisadores a defenderem que acadêmicos de marketing deveriam fazer o movimento de se aproximar do meio empresarial (KLAUS; EDVARDSSON, 2014). Para esses pesquisadores, tal aproximação traria resultados positivos, tanto para praticantes, quanto para acadêmicos. Aos primeiros, estar mais próximo do meio acadêmico os levaria a absorver mais facilmente a necessidade de realmente terem o consumidor como centro das atividades empresariais (GRÖNROOS, 2003). Aos segundos, essa proximidade poderia lhes dar um maior entendimento sobre a necessidade de gerarem "generalizações empíricas", que nada mais são do que conhecimentos que podem ser replicáveis em diferentes âmbitos, especialmente os empresariais (HUBBARD; LIDSAY, 2002). Fundamental para esse processo seriam Escolas de Negócios, pois são espaços onde conhecimento em marketing é criado e lecionado (especialmente para praticantes), mas que também servem de referência para o empresariado, particularmente por oferecerem consultorias a diferentes empresas e organizações; tais ações, portanto, mostram o interesse de tais escolas em manterem laços fortes com o meio empresarial (MORGADO, 2019).

Alguns autores (BRENNAN; ANKERS, 2004), por outro lado, não percebem o distanciamento entre os meios acadêmico e empresarial como algo negativo. Para pesquisadores que seguem essa linha, teoria e prática de marketing se diferem intrinsecamente, e devem permanecer separadas, para não haver interferência do meio empresarial a trabalhos acadêmicos, e vice-versa. Tais autores também questionam se praticantes de marketing deveriam ser os verdadeiros beneficiários de pesquisas acadêmicas da área, pois estudos em marketing deveriam, na verdade, servir a propósitos maiores, focados em ajudar a melhorar a qualidade de vida de pessoas e sociedades (HUNT, 2002).

\section{Empreendedorismo em contextos de baixa renda}

Entende-se como empreendedor aquele indivíduo que assume riscos e que tem a capacidade de buscar oportunidades, apesar da escassez de recursos (GOUGH et al., 2014). Embora a escolha por empreender possa ser movida por uma vontade de determinados indivíduos em explorar certas situações, em diversos outros casos, empreender é a única opção para algumas pessoas, especialmente para aquelas de baixa renda, seja porque não conseguem empregos, ou devido à sua premência de acrescer a verba familiar para se sustentarem (DEGEN, 2008) . Esse cenário parecer ser uma realidade no Brasil, onde a cada 100 empreendedores, 42 
empreendem por necessidade (GLOBAL ENTREPRENEURSHIP MONITOR, 2017). A possibilidade de empreender permite que o empreendedor não somente se ocupe profissionalmente, mas também empregue outros membros de sua família, que dificilmente teriam oportunidades profissionais em outras empresas, dadas as suas baixas qualificações (VALE; CORREAA; REIS, 2014). O empreendedorismo por necessidade, portanto, se torna um tipo de salvação para indivíduos de baixa renda e seus agregados (BERNER; GOMEZ; KNORRINGA, 2012), ajudando-os a minimizar sua condição de pobreza (SINGER, 2006).

A prática empreendedora, todavia, não vem fácil a indivíduos de baixa renda, pois diversos precisam empreender com poucos recursos - tanto profissionais, quanto (e especialmente) financeiros (ALVAREZ; BARNEY, 2014; COOPER et al., 1994). Uma forma de lidar com a falta de capital para exercer tal atividade tem sido por meio de microfinanciamentos garantidos para a abertura de pequenos negócios (KHAVUL, 2010). O acesso a tais formas de capital, inclusive, ajuda a expandir o potencial empreendedor dessas pessoas, que dificilmente descobririam ter esses dons se não tivessem os recursos para investirem em seus negócios (e em si) (MAHMOOD; HUSSAIN; MATLAY, 2014). Todavia, mesmo quando têm possibilidades de levantar capital, indivíduos de baixa renda sofrem com falta de conhecimento técnico para desenvolverem empreendimentos com diferenciais significativos (PEREDO; CHRISMAN, 2006). Acabam, então, se aventurando em atividades que requerem pouca experiência profissional, diversas vezes reproduzindo aquilo que realizavam anteriormente, em outros empregos (LAZEAR, 2004). A falta de um conhecimento inicial sobre como gerir determinado negócio leva tais indivíduos, então, a se engajarem com outros empreendedores em suas comunidades, mais experientes, a fim de aprenderem sobre aspectos básicos, para que possam operar seus empreendimentos, eventualmente, inclusive, tornandose parceiros em diferentes atividades (FERNÁNDEZ-SERRANO; ROMERO, 2013).

Mesmo tendo dificuldades para empreender - o que pode ser atribuído em parte por sua pouca educação formal (ACS; KALLAS, 2007) -, empreendedores de baixa renda conseguem manter seus negócios estáveis e lucrativos, além de gerar renda na própria comunidade (BRUTON et al., 2015; PRAHALAD, 2010). Isso ocorre porque seus modelos de negócios são únicos, quando comparados a empresas que não são originárias de contextos de baixa renda, sendo mais adequados, portanto, para atender a necessidades e desejos de seus consumidores locais. Dessa forma, criam vantagens competitivas difíceis de serem imitadas, até porque os ganhos financeiros alcançados por esses empreendedores, diversas vezes, retornam a suas comunidades, pois tais indivíduos também consomem dentro desse mesmo espaço geográfico (VISWANATHAN; ECHAMBADI; VENUGOPAL; SRIDHARAN, 2014).

Uma explicação para o motivo de tais modelos de negócios em contextos de baixa renda serem particulares, com baixas possibilidades de replicação, é a sua falta de planejamento formal, nos moldes que a literatura de gestão e marketing está acostumada (CARRIERI; PERDIGÃO; AGUIAR, 2014). Por exemplo, é comum, nesses casos, que o improviso e a espontaneidade sejam ações frequentes no dia a dia de tais empreendedores, sendo adotados em razão de situações distintas que comumente ocorrem durante a relação comercial com consumidores, e que demandam respostas imediatas desses profissionais (CARRIERI; PERDIGÃO; MARTINS; AGUIAR, 2018). No fim, são essas ações que tornam a relação entre empreendedores e seus clientes tão forte, pois geram empatia entre as partes, em um cenário no qual confiança é fundamental para haver trocas (VISWANATHAN; SRIDHARAN; RITCHIE; VENUGOPAL; JUNG, 2012).

Em razão das formas "alternativas" de gestão e marketing encontradas em tais empreendimentos, diversos desses empreendedores são tidos como indivíduos que transformam suas comunidades. Além de melhorarem suas vidas por conta de seus esforços e dedicação aos seus negócios, esses profissionais ajudam a melhorar a qualidade de vida de 
seus pares do mesmo local por meio de diferentes ações, tais como empréstimo de dinheiro a outros empreendedores, que ajudam a fortalecer o ecossistema financeiro e social desses contextos de baixa renda (SRIDHARAN; MALTZ; VISWANATHAN; GUPTA, 2014). Empreendedorismo em contextos de baixa renda, portanto, não é somente uma forma de sobrevivência para pessoas desse segmento; é também uma atividade com consequências mais amplas, associadas a crescimento coletivo, que trazem dignidade àqueles que sofrem com a falta de recursos, e que servem como um mecanismo de defesa contra as dificuldades associadas à pobreza (SINGER, 2006).

\section{Metodologia}

De maneira a alcançar o objetivo do estudo, foi realizada uma pesquisa exploratória qualitativa. Em vista do pouco conhecimento sobre o distanciamento de empreendedores em contextos de baixa renda com o meio acadêmico, entende-se que esse tipo de pesquisa é o mais adequado por gerar conhecimento inicial sobre o fenômeno sob análise. A escolha por realizar uma pesquisa qualitativa se deu por essa oferecer mais benefícios a pesquisadores e entrevistados para discutirem o tema em questão. Aos primeiros, pois podem explorar tópicos que venham a surgir durante as entrevistas, mas que não haviam sido imaginadas anteriormente. Aos segundos, porque lhes dá mais liberdade para expressarem as suas opiniões sobre diferentes assuntos relacionados ao fenômeno pesquisado (DUARTE, 2004).

Ao todo, foram feitas 17 entrevistas, sendo nove com professores universitários e oito com empreendedores em contextos de baixa renda. Sobre os primeiros, são docentes que lecionam disciplinas de marketing e de empreendedorismo em uma universidade privada do Rio de Janeiro. Esses entrevistados possuem experiências que variam entre dois e 21 anos de docência, além de todos possuírem algum grau de vivência empresarial, seja como consultores ou funcionários de empresas (de diversos tamanhos e indústrias).

Quanto ao segundo grupo de entrevistados, são donos de empreendimentos em comunidades localizadas no município do Rio de Janeiro, especificamente no Morro do Vidigal, na Rocinha e no Morro do Banco. Nenhum deles possui ensino superior completo; seus níveis de escolaridade variam entre básico incompleto e médio completo, havendo dois entrevistados que são técnicos em Administração. Seus anos de experiência como empreendedores variam entre três e 30 anos (em alguns casos, os entrevistados já tiveram mais do que um empreendimento, sendo considerado, portanto, o acúmulo de anos como empreendedor). $\mathrm{O}$ acesso a esses empreendedores se deu por meio de indicações, inicialmente, de conhecidos dos pesquisadores que moram nestas comunidades e, em seguida, dos próprios entrevistados.

A coleta de dados primários foi dividida em duas etapas: na primeira etapa, foram realizadas entrevistas em profundidade com os professores, na própria universidade, em salas reservadas, a fim de garantir privacidade para expressarem suas opiniões com maior precisão. Para a segunda etapa, foram realizadas entrevistas com os empreendedores, em seus respectivos estabelecimentos comerciais. $\mathrm{O}$ fato de essas entrevistas terem sido realizadas in loco permitiu aos pesquisadores verificarem algumas das práticas que os entrevistados alegavam realizar. Todas as entrevistas foram gravadas, a fim de serem transcritas posteriormente.

Para guiar as entrevistas foram desenvolvidos dois roteiros, um para cada perfil de entrevistado. $\mathrm{O}$ roteiro para as entrevistas com os professores buscou explorar a sua visão sobre teorias, conceitos e modelos de marketing que seriam essenciais para um empreendedor gerir adequadamente o seu negócio. Por sua vez, o roteiro das entrevistas com os empreendedores objetivou entender quais teorias, conceitos e modelos de marketing eram utilizados nas práticas comerciais desses indivíduos. Cabe destacar que, para as entrevistas com os praticantes, evitou-se utilizar termos específicos da literatura de marketing, tais como "posicionamento", "análise ambiental", etc. por serem desconhecidos aos entrevistados, sendo 
preferido perguntá-los de forma mais descritiva se adotavam, por exemplo, ações para se diferenciar dos concorrentes ou se comercializavam produtos para consumidores com perfis distintos.

A análise dos dados foi realizada em duas etapas, seguindo sugestões de Rubin e Rubin (2005) e Gummesson (2005). Inicialmente, as transcrições das entrevistas de professores e empreendedores foram analisadas utilizando o software Atlas/ti, a fim de codificar os dados coletados. A codificação usou como base o referencial teórico, mas também buscou extrair novos achados originários dos relatos dos entrevistados (RUBIN; RUBIN, 2005).

Seguindo sugestão de Guest, Bunce e Johnston (2006), a codificação foi iniciada com a atribuição de códigos à primeira entrevista realizada (que, no caso, foi com um professor). A partir dessa, foram criados 29 códigos. Repetiu-se o processo para a segunda entrevista, obtendo-se 7 novos códigos (além dos 29 que já haviam sido criados). À medida que novas rodadas de codificação eram realizadas, menos novos códigos eram criados por entrevistas, de forma que a partir da $14^{\mathrm{a}}$ entrevista analisada até a $17^{\mathrm{a}}$, novos códigos não foram mais criados. Segundo os autores, é nesse momento que se pode considerar que a pesquisa alcançou a saturação dos dados. Ao todo, foram criados 53 códigos nesse processo.

Após a codificação, iniciou-se a interpretação dos dados. Foram, então, gerados relatórios extraídos do Atlas/ti - de cada um dos códigos criados, com trechos dos relatos dos entrevistados. A partir desses, foi possível encontrar semelhanças e diferenças naquilo reportado sobre o fenômeno estudado. Esse processo comparativo dos relatos dos entrevistados é uma prática incentivada em pesquisas qualitativas de marketing (GUMMESSON, 2005) pois permite se chegar às categorias de análise da pesquisa.

As categorias de análise apresentadas no próximo item, portanto, foram formadas a partir de 53 códigos, divididos da seguinte forma: "O negócio do entrevistado" - 12 códigos; "Teorias e práticas de análise interna e externa" - 9 códigos; "Teorias e práticas de segmentação e posicionamento" -9 códigos; "Teorias e práticas do composto de Marketing" - 23 códigos.

\section{Análise dos resultados}

No presente item, é feita a análise dos dados, sendo dividido em cinco subitens que versam sobre o negócio e os empreendedores entrevistados; a visão de professores e empreendedores sobre a análise interna e externa de negócios; teoria e prática sobre segmentação e posicionamento de negócios; aproximação entre teoria e prática nos relatos sobre o composto de marketing.

\subsection{O negócio dos empreendedores em contextos de baixa renda}

Foram entrevistados oito empreendedores com negócios em comunidades da cidade do Rio de Janeiro. A seguir, discute-se as suas trajetórias profissionais e os seus empreendimentos.

O Mercado Pai \& Filha, criado por Danilo, em 2012, tem duas unidades no Morro do Vidigal. Inicialmente, o mercado somente vendia produtos de origem nordestina. A ideia surgiu a observar que faltava esse tipo de oferta em sua comunidade, embora houvesse demanda por tal: "Eu comecei com uma 'Casa do Norte'. Vi que tinha muito nordestino aqui no Vidigal e abri uma birosca com produtos do norte." Hoje, o empreendimento faz parte da Rede MultiEconomia, uma cooperativa de mercados voltados ao público de baixa renda.

A Barbearia Vintage surgiu em 2015 e se localiza no Morro do Vidigal. O empreendedor Felipe, que trabalha na área há 15 anos, começou a oferecer seus serviços em um espaço cedido pela mãe, com o objetivo de ser uma barbearia diferente das que já existiam no morro: “Tem outras barbearias aí bem feitas. Mas, essa daqui, em minha opinião, na comunidade, é a melhor. Meu sonho sempre foi abrir essa barbearia, uma barbearia 'top' aqui no morro, porque aqui não tinha nenhuma barbearia com técnica." 
O Super Rede Vidigal, outro mercadinho no Morro do Vidigal, surgiu em 2008, quando diversos empreendedores decidiram abandonar seus negócios por conta da violência. Arildo, seu proprietário, já atuava no ramo há 20 anos, mas em um espaço menor, e aproveitou o momento para investir: de um mercado de $70 \mathrm{~m}^{2}$, foi para um de $500 \mathrm{~m}^{2}$. Segundo Arildo: "A maior dificuldade que passei aqui foi violência... Com a violência, o governo tirou alguns benefícios daqui da comunidade... Muitos comerciantes foram embora, e eu acreditei no Vidigal, e investi nesse terreno." Hoje, seu negócio faz parte da Super Rede, uma rede de mercados voltados ao público de baixa renda. Além desse empreendimento, Arildo iniciou, em 2017, a construção do primeiro centro comercial do Vidigal, onde serão alugados 50 espaços. Segundo o empreendedor, a ideia é despertar o espirito empreendedor na comunidade, dar oportunidade para quem quer abrir seu próprio negócio e trazer investimento ao local.

O Mercadinho do Gaúcho, no Morro do Banco, foi aberto em 2014, quando o "Gaúcho" fícou desempregado. Com o dinheiro da rescisão do antigo emprego, decidiu abrir seu próprio negócio com a esposa Maria. A ideia de abrir um mercado surgiu quando perceberam que havia a necessidade de um comércio aberto após às $21 \mathrm{~h}$ na comunidade onde moram. Além disso, havia poucos com entrega a domicilio. Usando a experiência de trabalhos anteriores, como atendimento ao público, e o curso técnico em administração de Maria, deram início ao negócio.

A lanchonete Mac Morro, criada por Jana e seu marido em 2004, localiza-se no Morro do Banco. Ambos trabalhavam juntos em uma lanchonete, onde se conheceram, e decidiram abrir um comércio relacionado às atividades que já faziam. O nome do negócio surgiu da junção do nome da rede de fast-food McDonald's com morro, para remeter à ideia de comida de qualidade, rápida e de dentro da comunidade. Em 2018, iniciaram as vendas a domicílio.

O empreendedor "Bibiu", como é conhecido no Morro do Banco, é dono do Mercado e Padaria São João. Antes, em 1995, quando trabalhava como garçom, decidiu abrir uma pizzaria. A ideia surgiu observando um amigo que já atuava nesse mercado, e se ofereceu para ensiná-lo como fazer pizza. Bibiu conta: "Comecei onde eu morava. Botei quatro mesinhas na varanda e comecei devagarzinho. Depois, eu vim pra cá, onde hoje é o depósito do mercado, e depois fui pra onde é a pizzaria hoje em dia." Quanto ao surgimento do mercado, o empreendedor diz que em 2014, um primo lhe ofereceu o terreno para a construção. Bibiu não possuía conhecimento sobre esse negócio, mas apostou em sua capacidade de fazer o empreendimento prosperar.

O Mercado Céu e Mar, de propriedade de Carlos, surgiu em 2005 quando o empreendedor percebeu a necessidade de um comércio grande dentro da Rocinha. De acordo com o empreendedor: "Existia a necessidade de um mercadinho dentro da comunidade, na parte mais interior aqui da Rocinha. Na época, não existiam tantos. Eu fui o pioneiro." O mercado está localizado na rua principal da comunidade, onde há grande movimento de pessoas e é reconhecido por ser um dos maiores mercados dentro da comunidade.

Eduardo, dono do Açougue Lima Sales e do petshop Pelos \& Penas, decidiu abrir seu negócio na Rocinha quando a família aumentou e o salário já não supria mais suas necessidades. Usando seus conhecimentos em venda, decidiu abrir com um sócio uma espécie de mercado, focado mais na venda de carne fresca. Depois de consolidado o Açougue Lima Sales, decidiu abrir o petshop Pelos \& Penas, mesmo sem conhecimentos sobre esse novo mercado. Segundo ele, a maior dificuldade enfrentada até hoje é a violência, pois o mercado está localizado em uma das áreas mais perigosas da comunidade: "Violência afastou muitos clientes daqui."

As motivações para os entrevistados empreenderem foram ocasionadas tanto por enxergarem oportunidades, quanto por necessidade (DEGEN, 2008). Por um lado, percebiam demandas latentes em suas comunidades e se imaginavam aptos a atendê-las, como no caso de Felipe, quando abriu a Barbearia Vintage. Por outro lado, necessidades pessoais, motivadas pela 
carência de renda, seja em razão de desemprego ou aumento de custos familiares, fez com que seguissem o caminho do empreendedorismo, conforme ocorreu com Eduardo (dono do Açougue Lima Sales e do petshop Pelos \& Penas) e Gaúcho (Mercadinho do Gaúcho).

Cabe destacar, também, que enquanto alguns empreendedores dizem que a escolha por empreenderem em determinado negócio ocorreu porque já possuíam experiências passadas no ramo (conforme Jana, do Mac Morro, relata) (LAZEAR, 2004), outros indicaram que nunca haviam trabalhado com o serviço que é hoje o seu "ganha-pão" (como no caso de "Bibiu", dono do Mercado e Padaria São João), assumindo riscos para empreender (GOUGH et al., 2014).

\subsection{Detecção de oportunidades/ameaças e estruturação interna do negócio}

Segundo os professores entrevistados, um empreendedor de sucesso é aquele que tem senso de oportunidades: "Identifica uma lacuna de mercado, e coloca todo esse drive de realização que ele tem pra resolver esse problema" (Professor 7). Para isso, precisa estruturar o negócio antes da abertura, algo que pode ser um problema para alguns empreendedores, dadas as suas parcas condições financeiras (COOPER et al., 1994), conforme saliente o Professor 6: "Empreendedor por necessidade, não tem dinheiro, mas precisa trabalhar... Ele vai fazer alguma coisa que ele sabe fazer, e não necessariamente ele vai estruturar o negócio."

Foram poucos os empreendedores que relataram terem realizado algum tipo de análise ambiental para detectar oportunidades e ameaças antes de abrirem os seus negócios. Entre os que o fizeram, indicam que observaram qual tipo de negócio faltava em suas comunidades, mas sem necessariamente se preocupar em analisar todos os elementos de uma análise ambiental tradicional (ambientes econômico, político-legal, social, natural ou tecnológico), satisfazendo-se em verificar que não havia concorrentes na região vendendo o que pretendiam comercializar:

A gente viu que tinha necessidade de ter um mercadinho que ficasse aberto até tarde aqui... Chegava do trabalho, não tinha nada aberto (Maria).

Há 20 anos atrás, eram poucos os mercadinhos aqui dentro da Rocinha. Eu já abri observando essa carência (Carlos).

Eu queria abrir alguma coisa diferente... Com esse centro comercial, vou ganhar aluguel e vou ter investidores. Vou trazer investidores aqui pro local (Arildo).

Os demais empreendedores entrevistados não tiveram preocupações em realizar uma análise ambiental pois desconheciam a seu respeito, abrindo os seus negócios de acordo com as atividades que já estavam acostumados a realizar antes (LAZEAR, 2004).

Segundo os professores, entre os elementos essenciais a serem estudados em uma análise ambiental estão os concorrentes e os clientes. De acordo com o Professor 3: "O estudo do comportamento do consumidor vai tentar entender melhor porque os consumidores vão preferir ele, e não o concorrente." Todavia, são poucos os empreendedores que fazem análises de seus concorrentes. Os entrevistados sequer gostam de enxergar os seus concorrentes como uma "concorrência", pois associam o termo a competição não-saudável:

Não costumo analisar. Muita gente me pergunta aqui quem é o melhor da comunidade... Eu não gosto disso (Felipe).

Aqui na frente, esse mercadinho vende a mesma coisa que a gente vende, e eu não sei o preço deles nem nada. Tento cativar os meus clientes (Eduardo).

Possivelmente, o que pode explicar esse pensamento desses entrevistados é a ideia de que todos os empreendedores na comunidade estão gerenciando seus negócios como forma de “sobreviver" à pobreza (SINGER, 2006). Há um senso de que estão "no mesmo barco" e, por 
isso, não devem tentar ser melhores do que os concorrentes, pois isso significaria desempregar alguém "que pode estar necessitando". Entretanto, ao ignorar o que seus concorrentes estão fazendo, os empreendedores podem se prejudicar, pois passam a tomar decisões sem embasamento de informações, conforme o Professor 3 explica: "Qual é o papel da competição nisso, os competidores, que ambiente que esse empreendedor está inserido? ... Se ele não conhece um pouco disso, ele vai tomar as decisões com base... no bom senso. E as chances de ele tomar decisões que não são bem recebidas pelos consumidores é muito grande."

Entre os empreendedores que acreditam ser importante realizar análises de seus concorrentes, fazem-no para comparar produtos que são vendidos, preços e disposição de mercadorias nas outras lojas. Inclusive, não analisam somente os empreendimentos próximos aos seus, buscam também informações sobre as práticas de marketing de comércios similares até em outros países, conforme os relatos a seguir ilustram:

A gente está sempre ligado no que os concorrentes fazem, tanto de preço, quanto de arrumação... Agora mesmo, a gente fez uma modificação na loja, pra justamente criar um ambiente melhor pros clientes (Carlos).

Eu costumo ir a mercados maiores pra ver os preços. Também vou em feiras pra conhecer produtos novos... Quando eu viajo pra fora, eu observo mercados. Já estive no Estados Unidos, fui esse ano no Chile... Eu observo muito, e vejo se dá pra trazer alguma ideia pra cá (Arildo).

Quanto a estudar o comportamento de seus consumidores, todos os empreendedores disseram que tentam entendê-lo. Entretanto, esse esforço é feito de maneira informal, apenas Arildo sendo a exceção, pois realiza pesquisas de mercado dentro do seu estabelecimento comercial "pelo menos quatro vezes ao ano". Os demais entrevistados limitam-se a trocar informações com clientes por meio do aplicativo WhatsApp ou ouvir seus relatos verbalmente:

Não faço pesquisa, mas aqui tenho contato direto com cliente. Tem cliente que tem o hábito de ir à loja constantemente. Então, tenho esse contato com ele, temos essa liberdade mútua, tanto eu de perguntar, quanto dele também vir até mim e passar alguma coisa que ele está insatisfeito (Carlos).

Pergunto diretamente para o consumidor. Aqui, a gente conhece praticamente todo mundo. Então, se o cliente acha que não é bem atendido, a gente vai tentar saber o que aconteceu (Eduardo).

Foi possível perceber que os empreendedores que realizam pesquisas informais parecem não sentir a necessidade de uma pesquisa de mercado mais tradicional, pois possuem proximidade com seus clientes, tendo, então, liberdade para fazer perguntas a eles sobre a satisfação com o serviço. Segundo o Professor 7, é importante que empreendedores "se aproximem do cliente", visto que, além de entenderem melhor o cliente, estimulam a sua confiança. Todavia, vale ressaltar que a noção dos empreendedores de que "conhecem" todos os clientes e que, por isso, tais indivíduos teriam liberdade para fazer críticas a seus negócios é preocupante. É notório que consumidores não relatam a sua insatisfação a empresas, ainda mais quando são de contextos de baixa renda (HEMAIS; CASOTTI, 2017).

Outro ponto citado pelos professores para o sucesso de um negócio é a análise interna, pois, dessa forma, o empreendedor é capaz de definir forças e fraquezas, e, assim, entender no que precisa melhorar. Para entender melhor como isso era feito pelos empreendedores, os pesquisadores focaram em investigar se esses indivíduos tinham mecanismos de controle sobre as vendas de seus produtos/serviços, uma vez que o termo "análise interna" lhes soava estranho. A formalidade da linguagem torna textos acadêmicos pouco acessível a praticantes, o que contribui para o distanciamento entre os meios acadêmico e empresarial (EDWARDS, 
2005). No presente caso, entretanto, a formalidade linguística não parece uma questão, pois os termos usados pelo meio acadêmico sequer são conhecidos por esses empreendedores. Não há, portanto, um afastamento de uma parte a outra; há, sim, uma completa falta de entendimento sobre a existência de estudos que possam ajudar empreendedores a lidar de maneira mais adequada com questões relacionadas a negócios. Essa situação ocorreu não somente nesse caso, mas na maioria das vezes que termos mais técnicos eram mencionados aos entrevistados.

Todos os empreendedores entrevistados conheciam o produto/serviço mais vendido em seus estabelecimentos, mas somente alguns sabiam os menos vendidos. Entre aqueles que tinham informações completas sobre a comercialização, conseguiam tê-las pois possuíam um sistema administrativo no caixa: "Uso um programa administrativo para ter mais controle disso, porque trabalho com mais ou menos três mil produtos" (Danilo). Por meio desse sistema, os empreendedores recebem informações sobre quais produtos deveriam ser comprados ou quais não estavam vendendo adequadamente: "Através do programa administrativo de vendas, eu faço controle do estoque e sei qual produto tenho que parar de comprar... Sei o que está saindo mais, o que está perto do vencimento... Se estiver vencendo, é porque não está saindo (Maria).

O uso do sistema administrativo para controlar estoques é recomendado por alguns professores. Segundo o Professor 8: "No momento em que esses profissionais conhecem essas ferramentas e começam a botar elas em prática, isso passa a ser um norteador, um planejamento contínuo." Mesmo que essa seja a única forma de análise interna que os empreendedores realizem, tal sistema tem lhes ajudado a mais bem planejar as suas compras a partir de seus estoques, tornando esse processo menos informal (BRUTON et al., 2015).

\subsection{Segmentação e posicionamento: importantes teoricamente, porém pouco praticados}

Entre os conceitos mais importantes discutidos pelos professores entrevistados estavam os de segmentação e posicionamento de mercado. Eles defendem que saber diferenciar públicos a quem se deseja vender e a cada um deles oferecer um composto de marketing que atenda suas necessidades ou desejos é fundamental para ajudar a solidificar a lealdade do consumidor. Empresas que conseguem fazer isso adequadamente passam a ser vistas por seus clientes de forma diferenciada a seus concorrentes, o que consolida o posicionamento da organização.

Apesar de importantes, poucos empreendedores reconhecem que possuam estratégias de segmentação de mercado bem definidas. Entre aqueles que as praticam, relatam que:

Cada dia da semana, a gente tem um evento. Quarta-feira, é dia de churrasco à noite, porque é horário que vem gente mais velha... Trabalhamos com três tipos de marca diferentes, A, B e C: um bom, um médio e ruim. Assim, a gente não estende muito e atende todos tipos de cliente, até porque não temos espaço (Maria).

Porque a gente tem muitas promoções aqui. Se a pessoa está desempregada, ela pode vir e pagar por mês, ou até arrumar um emprego e vir acertar as contas. A gente também dá desconto de $10 \%$ pra quem é mototáxi ou estudante (Felipe).

Vale ressaltar que o Felipe, além de segmentar seu público por categoria de emprego (mototaxistas) e estudantes, ele usa o conceito para detectar grupos de consumidores desempregados e a eles oferecer pacotes especiais, por meio dos quais podem pagar por suas compras posteriormente. Sua ação vai ao encontro do que os Professores 7 e 8 alegam quando dizem, respectivamente, que: "O retorno financeiro é secundário à realização pessoal que o empreendedor sente." e "o empreendedor é alguém que faz diferença na sociedade." Essa relação mais pessoal ajuda a explicar o motivo pelo qual consumidores de baixa renda mantém o hábito de consumir produtos e serviços em estabelecimentos próximos a suas 
residências, mesmo que seus preços sejam mais altos do que os das grandes empresas (BARKI et al., 2016).

Entre os empreendedores que não praticam estratégias de segmentação de mercado, parece haver desconhecimento sobre essa prática e sua eficácia. Em sua visão, esses entrevistados devem "atender qualquer público", mas, até por uma questão geográfica, acabam se concentrando em vender somente a indivíduos que moram em suas comunidades. Em alguns casos, esses consumidores até vão além, e fazem compras de "produtos para suas patroas", comportamento esse também relatado por Castilhos e Rossi (2009), pois "o preço é mais vantajoso." Todavia, dificilmente isso poderia se configurar como um esforço dos empreendedores, pois nada fazem para diferenciar sua oferta a esses casos.

Diferentemente das estratégias de segmentação, todos os entrevistados acreditam que possuem um diferencial em relação a seus concorrentes. Em seus relatos, os entrevistados dizem que o atendimento a clientes é o que lhes distingue de outros estabelecimentos comerciais de suas comunidades. Alguns ainda citaram outros elementos como sendo seus diferenciais, tais como: "preço e qualidade e horário" (Maria); "o espaço" (Felipe); "personalidade do negócio, seja no atendimento, seja exposição da mercadoria, seja na apresentação da loja, porque de um modo geral, todo mundo aqui vende os mesmos produtos" (Carlos); "limpeza, comprometimento, seriedade, preço" (Arildo); "qualidade dos produtos" (Jana).

Os empreendedores entendem que seus negócios não são inovadores e, por isso, não estão isentos de serem copiados. O surgimento de concorrentes oferecendo os mesmos produtos ou serviços é uma realidade, dada a relativa facilidade que eles próprios tiveram em abrir os seus negócios. Assim, entendem que precisam sempre manter algum diferencial em relação aos demais estabelecimentos comerciais próximos aos seus, para que tenham uma vantagem competitiva. Bibiu reforça essa visão ao relatar que: "Padaria é uma coisa que qualquer um pode ter. Por isso, eu procuro ter uma farinha de boa qualidade, uma boa manteiga... um bom atendimento, uma boa limpeza, procuro fazer o melhor... Tenho que ter um diferencial.”

Mesmo não tendo completa consciência do que é posicionamento de mercado, e possivelmente não compreendendo tudo o que envolve o conceito (LILIEN, 2011), os empreendedores entendem que diferenciar os seus negócios é fundamental. Não foi possível verificar o quanto consumidores percebem tais diferencias, mas imagina-se que exista tal distinção, pois diversos empreendimentos operam há mais de 10 anos em suas comunidades. O estabelecimento de Bibiu merece menção particular porque é tão destacado em sua comunidade que chega a ser citado por moradores como "ponto de referência", quando precisam instruir empresas, tais como a operadora de luz do município, sobre como chegar a seus endereços.

\subsection{Composto de marketing: aproximação entre teoria e prática}

O composto de marketing é visto pelos professores como indispensável para a criação de um negócio diferenciado. Para eles, as decisões mais importantes de empreendedores giram em torno dos 4P's de marketing. Em relação a esses pontos, os empreendedores entrevistados conhecem bem os conceitos por trás dos 4P's, articulando adequadamente respostas sobre as práticas associadas a seu composto de marketing, aproximando-se daquilo ensinado no meio acadêmico (REPSOLD; HEMAIS, 2018). No que tange o Produto, por exemplo, os empreendedores montam o seu portfólio a partir de duas variáveis: giro do produto e demandas do consumidor. É importante, portanto, vender bens que não fiquem "parados nas prateleiras":

A (margarina) Qualy, eu sempre tenho que comprar, porque é conhecida e todo mundo compra. O giro é alto (Danilo). 
Produtos que aparecem na mídia, eu tenho que ter na loja. Se tem na Globo, se passa no Faustão, Luciano Huck, Silvio Santos... É uma mídia de graça pra mim! (Arildo)

Além do giro, os empreendedores também consideram as necessidades e os desejos de seus consumidores na hora de comprar os produtos que fazem parte de seu portfólio. Por lidarem com indivíduos de baixo poder aquisitivo, os entrevistados compõem as suas cestas de ofertas a partir da sensibilidade do consumidor a preços, podendo ter produtos mais caros, de melhor qualidade, mas obrigatoriamente oferecendo outros que sejam mais baratos:

Aqui, o pessoal quer um bom feijão, um bom arroz... Mas, também tem que ter um feijão de classe $\mathrm{C}$ (Arildo).

Sempre compro um produto de "linha", de boa qualidade. Por exemplo, eu tenho o suco Ades, que é um suco de boa qualidade, e um outro pior, mas que é mais barato. Nem todo mundo tem dinheiro pra comprar o de boa qualidade (Bibiu).

Ao agir dessa forma, os empreendedores vão em linha com o que o Professor 2 alega, quando diz que: "A capacidade de sobrevivência é muito maior quando você tem um foco maior no seu consumidor." O fato de diversos desses comerciantes serem moradores das comunidades onde possuem negócios os ajuda a conhecer melhor os seus consumidores (PRAHALAD, 2010). Acabam entendendo melhor, portanto, o que lhes agrada ou desagrada, embora, no fim, façam tal seleção com base em sua percepção ou opinião do que seus clientes desejam, sem que necessariamente isso seja, de fato, o que eles querem.

Esse "conhecimento" sobre os clientes também ajuda os empreendedores a saberem quais novos produtos teriam melhor aceitação. Isso é importante pois, segundo o Professor 1: "Empreendedores que buscam novidades têm um sucesso mais rápido do que os outros." A proximidade entre as partes permite que consumidores avisem aos empreendedores sobre novas ofertas. Todavia, apesar de levar em consideração as sugestões dos seus clientes, Carlos pondera sobre a compra do novo produto, pois: "nem tudo que se vende lá, se vende aqui."

A descoberta sobre novos produtos por parte dos empreendedores também ocorre quando são expostos a comerciais em mídias televisivas, jornalísticas ou pela Internet. Alternativamente, Danilo e Arildo conhecem as novidades por meio das associações de redes comerciais das quais são membros. Tais associações, segundo os entrevistados, promovem feiras, palestras e reuniões, a fim de apresentar novos produtos e ensinar estratégias de negócios:

Todo mês, tem reunião na sede da associação. Os fornecedores vão lá e apresentam os novos produtos ou os representantes chegam aqui e apresentam os novos produtos... A gente procura saber se já está saindo na mídia, se esse produto já está aparecendo na televisão, e, se tiver, a gente já compra (Arildo).

Às vezes, eles [em referências às associações] chamam a gente pra palestras e pra apresentar coisa nova. Como eu não sei escrever, eu fico prestando atenção, e depois tento botar aqui no mercado (Danilo).

Segundo os professores entrevistados, a forma correta de se determinar o Preço de produtos é analisando três elementos: custos de produção/compra do produto, preços praticados por concorrentes e demanda de consumidores a determinado preço. Por essa ótica, foi possível perceber que, em algum grau, os empreendedores entrevistados parecem adotar tais elementos em suas escolhas de apreçamento de produtos/serviços. Poucos, entretanto, alegam fazer os três.

Alguns empreendedores disseram que precificam os seus produtos utilizando uma margem sobre o custo de aquisição, levando em consideração o valor pago e o giro de estoque que o produto possui - quanto maior o giro, menor a margem de lucro. Uma forma como conseguem aumentar as suas margens é baixando custos, possível quando compram quantidades maiores 
de produtos. Para isso, os entrevistados alegam que, às vezes: "A gente também faz parceria com concorrentes: divido um caminhão de cerveja com meu concorrente, porque assim o preço da mercadoria cai" (Maria), achado esse que Fernández-Serrano e Romero (2014) também detectaram. Outros empreendedores, por sua vez, alegam que, além de um percentual adicional sobre o custo, comparam os seus preços aos dos concorrentes; prática considerada "fundamental" por alguns professores. Os relatos a seguir ilustram as estratégias de preços adotadas:

Se eu boto uma margem de $66 \%$ em um desodorante... eu compro por $\mathrm{R} \$ 5$, e vendo por $\mathrm{R} \$ 7,50$. Um desodorante roll-on dura três meses, e eu só ganhei R\$2,50. Agora, uma Coca-Cola, 'tá custando R \$1,79, isso aqui eu vendo todo dia (Danilo).

A gente analisa preços, porque tem barbeiros aqui que cobram preço muito alto, outros cobram muito baixo... e a gente tenta botar metade... A cada ano, as coisas aumentam, então, precisamos aumentar também o preço (Felipe).

Jana foi uma das poucas empreendedoras que demonstrou preocupação em pensar seus preços considerando custos, concorrentes e, também, consumidores: "A gente compara com lá fora... Por exemplo, esse hambúrguer artesanal, foi tudo pensado, tudo calculado, pra chegar em um valor também que não seja tão caro para os clientes." É possível que os empreendedores não consigam utilizar os três elementos no momento da precificação pois seus custos de compra são mais elevados em comparação a grandes estabelecimentos, devido à menor quantidade comprada. Assim, acabam tendo somente a alternativa de praticar uma margem sobre os custos, sem conhecer se seus consumidores aceitam consumir esses preços. Ainda há o fato de alguns entrevistados não gostarem de comparar os seus preços com os de concorrentes, conforme discutido anteriormente, o que acaba limitando a otimização de suas vendas.

Arildo e Danilo explicam que alguns preços praticados por eles são decididos pelas associações das quais são membros. Segundo Arildo, os preços dos produtos que estão nos encartes são feitos em conjunto: "Todo mês, a gente se reúne para fazer os encartes. A escolha de preços é democrática, a gente decide qual margem vamos botar juntos." Entretanto, Danilo, que participa de outra associação, diz que nem sempre os preços do encarte são justos: "Às vezes, eu compro no CEASA, e aplico o mesmo preço do encarte, porque não tem como eu vender um mamão por R $\$ 0,99$... Por isso, vou no CEASA, e compro os menores."

Por entenderem que preços são incentivadores da quantidade de compra, os empreendedores entrevistados alegam ajustar o quanto cobram, especialmente quando percebem que alguns produtos estão "encalhados". Arildo ilustra essa análise ao relatar o seguinte: "Quando vejo que um produto não está vendendo, jogo o preço dele lá embaixo, pra vê se vende mais rápido. Depois, eu paro de comprar ele."

Para o Professor 4: "Precificação é uma questão delicada, pro sucesso ou insucesso, pois é o que vai te manter vivo." Os empreendedores parecem entender essa importância atribuída ao preço, e talvez, por isso, tenham cuidado em defini-lo. Mesmo que não tenham embasamentos teóricos para fazê-lo (ACS; KALLAS, 2007), suas práticas se alinham àquelas definidas pelo meio acadêmico como sendo críticos para um apreçamento correto.

As preocupações com preços parecem refletir nas questões relacionadas ao Canal de Distribuição utilizado pelos empreendedores, mais especificamente quando falam de seus fornecedores. Todos alegam que negociam constantemente o valor das mercadorias que compram, de forma a obter melhores condições. Por isso, nem sempre trabalham com os mesmos fornecedores, pois buscam aqueles que poderão lhes proporcionar ofertas mais atrativas, como Maria relata: "Faço pesquisa de preço. São três fornecedores que vendem o mesmo tipo de produto. Aí, eu faço a cotação. Eu sou chata, negocio bastante." 
A possibilidade de ter acesso a múltiplos fornecedores e, assim, poder comparar preços de mercadorias é vista de maneira positiva pelos professores. Não depender de um fornecedor é importante para dar mais força aos empreendedores em suas negociações: maiores possibilidades de exigir melhores condições de compras, seja no preço em si ou nas condições de pagamento (a prazo, em parcelas, etc.) a até o tipo de produto comprado.

Há, todavia, empreendedores que colocam o custo do produto em segundo plano. Para eles, o mais importante é a reputação do fornecedor e a qualidade dos bens que oferecem: "Geralmente, fazemos degustação, até a gente ver se o produto vale a pena... Na verdade, desde que a gente abriu, são os mesmos fornecedores." (Jana) Sua lógica se baseia no pensamento de que seu estabelecimento comercial precisa manter uma boa imagem quanto àquilo que comercializa, uma vez que isso é um diferencial do negócio e garante um fluxo contínuo de recompras de seus consumidores: "Não adianta comprar produto ruim, porque aí o cliente só vai vir comprar aqui uma vez só." (Eduardo)

A preocupação dos empreendedores com seu canal de distribuição inclui atenção à arrumação do espaço físico de seus estabelecimentos comerciais, de forma a torná-los o mais rentáveis possível. Danilo, por exemplo, desenhou o layout de seu mercadinho buscando forçar consumidores a circularem dentro da loja, e, com isso, serem expostos aos diversos produtos que comercializa: "Você sabe porque o açougue fica no final do mercado? É pro cliente ter que passar por todo mercado antes de chegar lá... A Coca-Cola também." (Danilo) Felipe, por sua vez, aproveita de outra forma: em sua barbearia, possui um espaço dedicado à venda de roupas e sapatos. Os produtos são vendidos em parceria com outros empreendedores - achado que, novamente, vai ao encontro dos de Fernández-Serrano e Romero (2014).

As estratégias de Produto, Preço e Distribuição realizadas pelos empreendedores são complementadas por ações de Promoção. A adoção da comunicação de marketing é importante para o sucesso de qualquer empreendimento comercial pois, segundo o Professor 2: "Não existe cliente potencial se ele não conhece você. É importante saber propor bem para seus clientes, pois esses divulgam seus produtos/serviços." $\mathrm{O}$ uso de propagandas em mídias tradicionais, mais caras, não é uma realidade para empreendedores em contextos de baixa renda (PARENTE; BARKI, 2006). Alguns, então, utilizam meios gratuitos para divulgar seus negócios, tais como mensagens em redes sociais, e realizam promoções de vendas para atrair consumidores:

No WhatsApp, Facebook.... Também fazemos eventos. Toda quartafeira é dia de churrasco aqui, porque sempre tem jogo e o pessoal gosta de assistir aqui (Maria).

No dia da festa de inauguração, nós demos tickets pra cortar cabelo de graça... A gente tem página no Facebook, no Instagram, e bota as promoções lá (Felipe).

Outros empreendedores, todavia, pouco se esforçam em adotar ações dessa natureza, por não acreditarem que possam trazê-los significativos benefícios. Acabam confiando mais no bocaa-boca positivo de seus consumidores ou, mesmo, na localização de suas lojas, por estarem em locais com grande fluxo de pedestres, facilitando a sua visibilidade: "Não faço divulgação. Mas, aqui é um lugar que tem muito movimento. Então, não preciso.” (Bibiu)

Todavia, o elemento de comunicação mais utilizado pelos empreendedores é o próprio empreendedor e os seus vendedores, em diversos casos por causa da falta de recursos para outros tipos de investimentos desse tipo (GOUGH et al., 2014). Os entrevistados falam ativamente a respeito de seus negócios para consumidores, especialmente quando possuem promoções de vendas que possam interessar o público. Acabam, então, virando "anúncios ambulantes", conforme um professor descreve, ao falar sobre os esforços de empreendedores para divulgarem seus negócios. 
Quanto aos vendedores, alguns empreendedores mostram-se bastante atentos em qualificá-los para atenderem o consumidor, seja pagando para que façam cursos ou usando os seus fornecedores para tal finalidade. Maria, por exemplo, alega que oferece curso de reciclagem, atendimento e apresentação a seus empregados, enquanto que Jana e Danilo ministram tais treinamentos por conta própria. Carlos, por sua vez, indica que os próprios fornecedores oferecem treinamentos aos funcionários, algumas vezes até fora do mercado. Bibiu, todavia, não empreende esforços nesse sentido, mas se preocupa em conversar com seus funcionários, a fim de orientá-los sobre como deseja que atendam os clientes: "Normalmente, eu converso com eles, digo que atendimento é importante. Se você chega em um lugar e encontra um funcionário com 'cara fechada', com certeza você não vai voltar ali." Dentre os empreendedores, Arildo é o que mais investe na qualificação de funcionários: "Fazemos pesquisa com os colaboradores e damos cursos. Eu procuro sempre aprimorar, porque a mão de obra está muito complicada!... Faço treinamento com meus funcionários quatro vezes ao ano. Tenho um RH para fazer isso. Além disso, tenho psicóloga que vem conversar com eles." Além de uma sala de reunião, o prédio do mercado de Arildo conta com um refeitório para funcionários, uma igreja e uma academia. $\mathrm{O}$ empreendedor conta que o espaço onde está a academia não era utilizado, então, decidiu alugá-lo para outro empreendedor. É importante que empreendedores em contextos de baixa renda que sejam bem-sucedidos estimulem outros a também conseguirem obter sucesso ao empregá-los, pois isso geraria mais empregos e, por consequência, maior circulação de dinheiro dentro de suas comunidades (PRAHALAD, 2010). Nesse caso, Arildo se destaca, pois emprega e qualifica 68 pessoas do Morro do Vidigal.

A valorização e a capacitação de funcionários, segundo os professores entrevistados, são fundamentais para aumentar o seu comprometimento com o negócio, facilitando a integração entre eles, suas funções, seus colegas e seus empregadores: "o trabalho em equipe é essencial, pois ninguém empreende sozinho... é importante você ter outros olhares". Para isso, é importante que os empreendedores tenham um "perfil de líder", pois conseguem, assim, servir de exemplo aos seus funcionários e orientá-los quanto ao que se espera deles.

\section{Considerações Finais}

O presente trabalho teve o objetivo de analisar como empreendedores em contextos de baixa renda operam seus negócios, a fim de verificar o quanto suas práticas se aproximam/distanciam de ensinamentos do meio acadêmico. Para isso, foram realizadas entrevistas com professores universitários e empreendedores com esse perfil particular, a fim de ouvir ambas as partes quanto às práticas que empreendedores devem adotar pra serem bem sucedidos. A partir da análise dos dados, foi possível chegar a algumas considerações finais. $\mathrm{O}$ distanciamento entre os meios acadêmicos e empresarial ficou evidente nesta pesquisa, principalmente porque diversos empreendedores entrevistados tiveram pouco acesso a estudos formais, ainda mais em nível universitário, onde discussões sobre empreendedorismo e marketing são mais evidentes. Entretanto, foi possível perceber que algumas teorias, conceitos e modelos de marketing são adotados, em algum grau, por todos os empreendedores. A valorização do consumidor, por exemplo, é entendida como a alma do negócio, pois, sem satisfazê-los, especialmente com bom atendimento, é difícil prosperar. Em contextos de baixa renda, consumidores são mais do que clientes aos comerciantes; são, até, quase amigos. Por isso, empreendedores que convivem com pobreza acabam se envolvendo com questões sociais, tais como desemprego, e pensando em como lidar com essas adversidades (SINGER, 2006).

Embora pratiquem teorias, conceitos e modelos de marketing em algum grau, não há um entendimento por parte de empreendedores em contextos de baixa renda que aquilo que fazem possua uma nomenclatura e uma forma específica de executá-la, segundo o meio acadêmico. 
Talvez, por isso, junto ao fato de terem pouco acesso a estudos universitários (PEREDO; CHRISMAN, 2006), empreendedores desse contexto não adotem tais práticas em sua íntegra. Todavia, seguir princípios acadêmicos não parece ser algo que busquem; para eles, suas práticas e conhecimentos, mais do que teorias, são suficientes para serem bem sucedidos.

Aspectos relacionados à implementação do composto de marketing parecem ser mais tangíveis aos empreendedores e, por isso, alinham-se àquilo que o meio acadêmico prega como sendo fundamental para o bom gerenciamento de um empreendimento. Entretanto, questões mais estratégicas e táticas relacionadas a análise ambiental, pesquisas com consumidores, segmentação e posicionamento de mercado, que são conceitos mais abstratos e demandam maior conhecimento acadêmico sobre a forma de estruturar tais análises, fogem à capacidade de empreendedores em contextos de baixa renda de implementá-los integralmente. Mesmo assim, diversos desses tiveram êxito profissional, tornando-se, inclusive, referências em suas comunidades. $\mathrm{O}$ quanto mais bem-sucedidos poderiam ser esses empreendedores se conhecessem todas as teorias, os conceitos e os modelos de marketing ensinados no meio acadêmico é uma questão que merece maior reflexão.

A literatura de marketing que discute o distanciamento entre os meios acadêmico e empresarial pouco explora esse afastamento quando o praticante é um empreendedor em contextos de baixa renda. Como pôde-se verificar, não é possível afirmar que há necessariamente um maior ou menor distanciamento desses indivíduos com o meio acadêmico em comparação a seus pares em grandes empresas (KLAUS; EDVARDSSON, 2014). Há, simplesmente, uma completa falta de conhecimento sobre a existência de discussões a esse respeito no meio acadêmico, o que é diferente daquilo que ocorre com o empresariado mais tradicional, que escolhe se afastar por considerar as pesquisas desse meio irrelevante para o seu negócio (REPSOLD; HEMAIS, 2018). Caberia, então, ao meio acadêmico se aproximar desses indivíduos e mostrá-los teorias, conceitos e modelos de marketing que poderiam lhes ser úteis, ajudando-os, assim, a potencialmente se tornarem mais transformadores em suas comunidades.

O presente estudo é apenas uma contribuição para começar a entender melhor o fenômeno analisado. Para que mais conhecimento a seu respeito seja gerado, estimula-se que novos estudos sejam feitos em linha com o atual. Para pesquisadores (ou praticantes) interessado no assunto, sugere-se, então, que analisem em maior profundidade, por exemplo, as diferenças entre empreendedores membros de associações de rede e aqueles que não possuem qualquer tipo de auxílio administrativo. Isso permitiria entender melhor o impacto que tais associações possuem no negócio, visto que a estruturação e os auxílios recebidos mostram-se como bastante vantajosos a seus associados. Outra sugestão seria um estudo sobre a percepção do consumidor de baixa renda em relação aos negócios dentro e fora da comunidade, para entender a sua visão a respeito de ambos os tipos de varejistas e sua relação com cada um. Seria possível, dessa forma, compreender com maior detalhe o que cada um desses tipos de empreendimentos oferece de vantagens e desvantagens a esse segmento de mercado. 


\section{REFERÊNCIAS}

ACS, Z., KALLAS, K. (2008) State of Literature on Small- to Medium-Sized Enterprises and Entrepreneurship in Low-Income Communities. In: YAGO, G.; BARTH, J.; ZEIDMAN, B. (Eds). Entrepreneurship in Emerging Domestic Markets. Boston: Springer.

ALMEIDA, A.; ANDRADE, J.; FARINA, M. Conhecimento de Marketing: disseminação junto aos profissionais e contribuição da academia. Revista ADM.MADE, v.14, n.2, 2010.

ALVAREZ, S. A.; BARNEY, J. B. Entrepreneurial Opportunities and Poverty Alleviation. Entrepreneurship: Theory and Practice, v.38, n.1, p.159-184, 2014.

BAINES, P.; BRENNAN, R.; GILL, M.; MORTIMORE, R. Examining the academic/commercial divide in marketing research. European Journal of Marketing, v.43, n.11/12, p.1289-1299, 2009.

BARKI, E.; ZAMBALDI, F.; LOURENÇO, C.; CASTRO, C. Store patronage and retail competition in emerging markets. International Journal of Business and Systems Research, v.10, n.1, p.62-77, 2016.

BERNER, E.; GOMEZ, E; KNORRINGA, P. 'Helping a Large Number of People Become a Little Less Poor': The Logic of Survival Entrepreneurs. European Journal of Development Research, v.24, p.382-396, 2012.

BÔAS, B.V. Pobreza extrema aumenta $11 \%$ atinge 14,8 milhões de pessoas. Valor Econômico, 12 abr. 2018. Disponível em: http://www.valor.com.br/brasil/5446455/pobrezaextrema-aumenta-11-e-atinge-148-milhoes-de-pessoas. Acesso em: 28 jun. 2018

BRENNAN, R.; ANKERS, P. In search of relevance: Is there an academic-practitioner divide in business-to-business marketing? Marketing Intelligence \& Planning, v.22, n.5, 2004.

BROWNE , S.; CUDDIHY, L. Questioning the currency of marketing planning today. Irish Marketing Review, v.21, n.1-2, p.49-57, 2011.

BRUTON, G.; AHLSTROM, D.; SI, S. Entrepreneurship, poverty, and Asia: moving beyond subsistence entrepreneurship. Asia Pacific Journal of Management, v.32, n.1, p.1-22, 2015.

CARRIERI, A.; PERDIGÃO, D.; AGUIAR, A. A gestão ordinária dos pequenos negócios: outro olhar sobre a gestão em estudos organizacionais. Revista de Administração (São Paulo), v.49, n.4, p.698-713, 2014.

CARRIERI, A.; PERDIGÃO, D.; MARTINS, P.; AGUIAR, A. A Gestão Ordinária e suas práticas: o caso da Cafeteria Will Coffee. Revista de Contabilidade e Organizações, v.12, e141359, p.1-13, 2018.

CASTILHOS, R.; ROSSI, C. A. Subindo o morro: consumo, posição social e distinção entre famílias de classes populares. In: ROCHA, A.; SILVA, J. (Orgs.) Consumo na Base da Pirâmide - estudos brasileiros. Rio de Janeiro: Mauad X, 2009.

COOPER, A.; GIMENO-GASCON, F.; WOO, C. Initial human and financial capital as predictors of new venture performance. Journal of Business Venturing, v.9, n.5, 1994.

CROSIER, K. How effectively do marketing journals transfer useful learning from scholars to practitioners? Marketing Intelligence and Planning, v.22, n.5, p.540-556, 2004.

DEGEN, R. Empreendedorismo: uma filosofia para o desenvolvimento sustentável e a redução da pobreza. Revista de Ciência da Administração, v.10, n.21, p.11-30, 2008.

DUARTE, R. Entrevistas em pesquisas qualitativas. Curitiba: Educar em Revista, 2004.

EDWARDS, M. Organizational identification: a conceptual and operational review, International Journal of Management Reviews, v.7, n.4, p.207-230, 2005.

FERNÁNDEZ-SERRANO, J.; ROMERO, I. Entrepreneurial Quality And Regional Development. Papers in Regional Science, v.92, n.3, p.495-513, 2013.

GERBELLI, L.; SARMENTO,G. Empreendedorismo deve gerar metade das vagas de trabalho no país este ano, diz pesquisa. Disponível em: 
$<$ https://g1.globo.com/economia/noticia/empreendedorismo-deve-gerar-metade-das-vagasde-trabalho-no-pais-este-ano-diz-pesquisa.ghtml>. Acesso em: 16 abr 2018.

GLOBAL ENTREPRENEURSHIP MONITOR. Empreendedorismo no Brasil: 2016. Curitiba: IBQP, 2017. 208 p.

GOUGH, K,; LANGEVANG, T.; NAMATOVU, R. Researching entrepreneurship in lowincome settlements. Environment and Urbanization, v. 26, n. 1, p. 297-311, 2014.

GRÖNROOS, C. Taking a customer focus back into the boardroom: can relationship marketing do it? Marketing Theory, v.3, n.1, p.171-173, 2003.

GUMMESSON, E. Qualitative research in marketing: Road-map for a wilderness of complexity and unpredictability. European Journal of Marketing, v.39, n.3/4, p.309, 2005.

HEMAIS, M.; CASOTTI, L. Por que reclamar? Melhoria de autoestima e cidadania de um grupo de baixa renda a partir dos serviços de uma agência de defesa do consumidor. Revista Eletrônica de Administração, v.86, n.2, p.83-109, 2017.

HUBBARD, R.; LINDSAY, R. How the emphasis on 'original' empirical marketing research impedes knowledge development. Marketing Theory, v.2, n.4, p.381-402, 2002.

HUNT, S. Marketing as a profession: on closing stakeholder gaps. European Journal of Marketing, v.36, n.3, p.305-312, 2002.

KHAVUL, S. Microfinance: Creating opportunities for the poor? Academy of Management Perspectives, v.24, n.3, p.58-72, 2010.

KLAUS, P.; EDVARDSSON, B. The road back to relevance - how to put marketing (and marketing scholars) back on the Top Managements' agenda. Journal of Services Management, v.25, n.3, p.166-170, 2014.

LAZEAR, E. Balanced skills and entrepreneurship. American Economic Review, v.94, 2004.

LEE, N.; GREENLEY, G.E, The theory-practice divide: thoughts from the Editors and Senior Advisory Board of EJM. European Journal of Marketing, v.44, n.1-2, p.5-20, 2010.

LILIEN, G. Bridging the academic-practitioner divide in marketing decision models. Journal of Marketing, v.75, n.4, p.196-210, 2011.

MAHMOOD, S.; HUSSAIN, J.; MATLAY, H. Optimal microfinance loan size and poverty reduction amongst female entrepreneurs in Pakistan. Journal of Small Business and Enterprise Development, v.21, n.2, p.231-249, 2014.

MORGADO, A. Bridging the academic-practitioner divide in marketing: the role of Business Schools. In: PINHEIRO, M.; ESTIMA, A.; MARQUES, S. Evaluating the Gaps and Intersections Between Marketing Education and the Marketing Profession, Hershey: IGI Global, 2019. 39 p.

PARENTE, J.; BARKI, E. Varejo na baixa renda. GV Executivo, v.5, n.1, p.39-43, 2006.

PEREDO, A.; CHRISMAN, J. Toward a theory of community-based enterprise. Academy of Management Review, v.31, n.2, p.309-332, 2006.

PRAHALAD, C. K. A riqueza na base da pirâmide. Porto Alegre: Bookman, 2010. 408 p.

REPSOLD, F. HEMAIS, M. Distanciamento em marketing entre acadêmicos e praticantes.

Brazilian Business Review. v.15, n.1, p.68-87, 2018.

RUBIN, H.; RUBIN, I. Qualitative interviewing. Thousand Oaks: Sage, 2005.

SINGER, A. Business strategy and poverty alleviation. Journal of Business Ethics, v.66, n.2-3, p.225-231, 2006.

SOARES, J. O que explica o aumento da pobreza extrema no Brasil? Disponível em: https://economia.uol.com.br/noticias/redacao/2018/04/17/o-que-explica-o-aumento-dapobreza-extrema-no-brasil.htm. Acesso em: 20 jun. 2018. 
SRIDHARAN, S.; MALTZ, E.; VISWANATHAN, M.; GUPTA, S. Transformative Subsistence Entrepreneurship: A Study in India. Journal of Macromarketing, v.34, n.4, p.486-504, 2014.

STANTON, A. Bridging the academic/practitioner divide in marketing: An undergraduate course in data mining. Marketing Intelligence \& Planning, v.24, n.3, p.233-244, 2006.

VALE, G.; CORRÊA, V.; REIS, R. Motivações para o Empreendedorismo: Necessidade Versus Oportunidade? Revista de Administração Contemporânea, v.18, n.3, p.311-327, 2014.

VISWANATHAN, M.; ECHAMBADI, R.; VENUGOPAL, S.; SRIDHARAN, S. Subsistence Entrepreneurship, Value Creation, and Community Exchange Systems: A Social Capital Explanation. Journal of Macromarketing, v.34, n.2, p.213-226, 2014.

VISWANATHAN, M.; GAJENDIRAN, S.; VENKATESAN, R. Enabling consumer and entrepreneurial literacy in subsistence marketplaces. Springer, 2008.

VISWANATHAN, M.; SRIDHARAN, S.; RITCHIE, R.; VENUGOPAL, S.; JUNG, K. Marketing Interactions in Subsistence Marketplaces: A Bottom-Up Approach to Designing Public Policy. Journal of Public Policy and Marketing, v.31, n.2, p.159-177, 2012.

WIERENGA, B. On academic marketing knowledge and marketing knowledge that marketing managers use for decision-making. Marketing Theory, v.2, n.4, p.355-362, 2002. 